\title{
Use of Porous Polyethylene Implants in Nasal Reconstruction
}

\author{
${ }^{1}$ Natasha Choudhury, ${ }^{2}$ Joe Marais \\ ${ }^{1}$ Registrar, Department of ENT, Northwick Park Hospital, Watford Road, Harrow, London, United Kingdom \\ ${ }^{2}$ Consultant Surgeon, Department of ENT, Northwick Park Hospital, Watford Road, Harrow, London, United Kingdom
}

Correspondence: Natasha Choudhury, Registrar, Department of ENT, Northwick Park Hospital, Watford Road, Harrow, London HA1 3UJ, United Kingdom, Phone: 07815 898583, Fax: 01371275894, e-mail: natashamasood1 @ aol.com

\section{ABSTRACT}

Introduction: Patients undergoing complex rhinoplasty, following previous trauma or cartilage deteriorating disease processes, present a surgical challenge. The availability of septal cartilage maybe limited, and alternative graft materials should be considered.

Methods: A retrospective study of our experience using the porous polyethylene (Medpor ${ }^{\circledR}$ ) implant in nasal reconstruction was conducted. The indications for surgery are reviewed and the surgical outcomes noted. We also review the literature on available nasal implants and discuss their advantages and disadvantages.

Results: A total of 22 Medpor $^{\circledR}$ nasal implants were used for augmentation rhinoplasty over a 6 and half years period. Three patients experienced a surgical complication, including one slipped dorsal implant, and two patients with graft extrusion. Both of these two patients had concomitant disease processes that would have resulted in a poor tissue microenvironment, which may have contributed to their graft failures.

Conclusion: In our experience, the Medpor ${ }^{\circledR}$ implant has proved very successful in patients requiring complex rhinoplasty, in a normal host tissue microenvironment.

Keywords: Augmentation rhinoplasty, Porous polyethylene, Medpor, Nasal reconstruction.

\section{INTRODUCTION}

Complex augmentation rhinoplasty to correct both functional and cosmetic deformities remains a challenge for the rhinoplasty surgeon. The skeletal structure maybe severely deformed from previous trauma or underlying disease processes. These resulting deformities may occur together with significant soft tissue disfigurement. Correction of all these aspects requires careful selection of graft material with a refined surgical technique. The correct choice of graft material for nasal reconstruction is critical. A number of grafts are now available, which is a pertinent indication that there is no single 'perfect' graft material available. Many characteristics have been indicated for an 'ideal' implant (Table 1), but there is still no single autologous or alloplastic material that fulfils all these criteria.

For complex cases of nasal reconstruction, a considerable volume of graft may also be required. Autogenous tissues, including cartilage and bone, have been the primary choices to date. The principal reason for this has been their promise of biocompatibility, thereby reducing the risks of graft infection and rejection. However, autogenous grafts have their own limitations. These include donor site morbidity, a limited supply, potential warping of cartilage grafts and unpredictable bony resorption. These disadvantages have led to a surgence in the search of an alternative, suitable synthetic graft material. A number of alloplastic materials are now available, each with their own advantages and limitations. These include nonporous materials, which may provide smooth, soft tissue augmentation, but lack stability due to their inability to demonstrate host tissue in-growth. Alternatively, a number of porous materials are now available, which promote fibrovascular in-growth with the surrounding host tissue, which

\section{Table 1: Properties of an ideal graft material}

Properties

Readily available

Unlimited quantities

Inexpensive

Inert

Nontoxic

Noncarcinogenic

Easy to sculpt

Easily camouflaged

Provide volume

Provide mechanical support

Should interact favorably with surrounding tissues

Maintain its form over time

Resist trauma, infection and extrusion

Remain easy to remove 
provides both mechanical stability and a reduced risk of infection. Their main limitation, however, is in the difficulty experienced in removing such grafts, if this should be required. Table 2 provides a broad summary of the advantageous and limiting features associated with autogenous and alloplastic grafts.

Here, we present our experience in the reconstruction of complex nasal deformities using porous polyethylene $\left(\right.$ Medpor $^{\mathbb{B}}$ ) implant (Porex Surgical Inc., College Park, Newnan, GA). Medpor ${ }^{\circledR}$ implants are manufactured from linear high-density polyethylene through a process of sintering in which small particles are fused together at high temperature and pressure. They are composed of 50\% porous volume with pore size ranging from 100 to $250 \mu \mathrm{m}$. The large degree of porosity facilitates fibrovascular ingrowth of the hosts' tissue, thus promoting incorporation of the implant into the surrounding soft tissue and graft stability. The fibrovascular in-growth has also been suggested to aid in preventing infection. ${ }^{1}$ This promising feature has led to the use of Medpor ${ }^{\circledR}$ surgical implants for a number of surgical purposes, including craniofacial reconstruction, ${ }^{2,3}$ orbital implantation, ${ }^{4,5}$ microtia reconstruction ${ }^{6-8}$ and nasal reconstruction. ${ }^{9-12}$ Interestingly, although the use of Medpor ${ }^{\mathbb{R}}$ implants in rhinoplasty surgery is widely described among the plastic surgery literature, there were no identifiable articles among any ENT journals, from a search of the MEDLINE database from 1966 to 2010, using rhinoplasty, Medpor and porous polyethylene as key identifiable words.

The use of Medpor ${ }^{\circledR}$ implants for augmentation rhinoplasty is facilitated by the availability of a number of ready-made nasal implants that are available in a variety of customised shapes, including preformed nasal dorsal grafts, alar battens and columellar struts, which also come in a number of different sizes. Alternatively, the graft material is also available as blocks or sheets and the firm nature of the graft material allows for refined carving with a sharp instrument, without collapsing the pore structure. The implant also has a smooth exterior surface which provides good contour adaptability and a series of conical ridges on its undersurface that enables easy bending to mould to shape and suitable strength. ${ }^{2}$

Based on these advantageous features of porous polyethylene grafts, the senior author has chosen to use the Medpor ${ }^{\circledR}$ implant for nasal reconstruction in a selected group of patients requiring complex augmentation rhinoplasty. For these patients, the use of autologous septal cartilage was not possible due to the lack of sufficient cartilage material. Alternatively, the potential risks and donor site morbidity from harvesting other autologous grafts was considered unacceptable to either patient or surgeon, or both, in this group of patients.

\section{MATERIALS AND METHODS}

A retrospective case note review of augmentation rhinoplasty cases that utilized the Medpor ${ }^{\mathbb{R}}$ nasal implant between February 2004 and September 2010 was performed. Patients were selected for inclusion where there was unavailable or insufficient septal cartilage to use as graft material. Indications for surgery, including the nature of deformities or significant comorbidities were reviewed, and surgical outcomes, including complications, were noted.

\begin{tabular}{lll} 
& Table 2: Advantages and disadvantages of autogenous and alloplastic grafts \\
& Advantages & Disadvantages \\
\hline Autogenous & No biocompatibility issues & Limited quantity \\
& Low infection rates & Morbidity of tissue harvest \\
& Low rejection, extrusion & \\
Favorable graft-host interaction & \\
Host tissue in-growth & Inflammatory host response: \\
& Stability & Infection, rejection, extrusion \\
& Reduced potential infection & Migration (nonporous implants) \\
& Soft, pliable, easily sculpted & Difficult removal (tissue in-growth) \\
\hline
\end{tabular}

Table 3: Results (numbers in bold denotes grafts that were complicated by extrusion)

\begin{tabular}{lcccc} 
Indication & $\begin{array}{c}\text { Previous } \\
\text { septoplasty }\end{array}$ & $\begin{array}{c}\text { Previous septal } \\
\text { hematoma }\end{array}$ & $\begin{array}{c}\text { Granulomatous } \\
\text { disease }\end{array}$ & $\begin{array}{c}\text { Cocaine abuse } \\
\text { Total number of patients } \\
\text { Graft site }\end{array}$ \\
- Dorsum & 9 & 3 & 2 & 1 \\
- Columella & 9 & 3 & 2 & $\mathbf{1}$ \\
- Alar & 4 & 0 & 0 & $\mathbf{1}$ \\
\hline
\end{tabular}




\section{SURGICAL TECHNIQUE}

All patients underwent surgery under a general anesthetic and received a single dose of $8 \mathrm{mg}$ dexamethasone on induction of anesthesia. For all cases, surgery was performed via an external septorhinoplasty approach via a transcolumellar approach through an inverted ' $\mathrm{V}$ ' skin incision. Precustomized shapes of graft were used and carved down to size using a blade, for each patient, after determining the precise length of graft required. The grafts were immersed in $0.5 \%$ chloramphenicol drops (Bausch \& Lomb), prior to placement. Dorsal grafts were placed into a small subcutaneous pocket, as an on-lay graft above the nasal bone and upper lateral cartilages and inferiorly to the lower lateral cartilages with a $4 / 0$ vicryl suture. A transcutaneous parachute suture using $2 / 0$ vicryl rapide was also used through the overlying skin of the dorsum, if the dorsal graft was not stabilized sufficiently through anchoring sutures to adjacent cartilage. Columellar grafts were secured into a columellar pocket using $4 / 0$ vicryl. Alar batten grafts were inserted into a sleeve within a soft tissue pocket and secured with $4 / 0$ vicryl. All skin incisions were meticulously closed using $6 / 0$ prolene and bilateral gelonet packs were placed postoperatively for 6 hours. External taping and Plaster of Paris were applied for 10 days. All patients were discharged on the same day following surgery, with a 10day course of oral antibiotic treatment. They were all routinely followed up at 10 days for plaster removal and 3 months for a final check with postoperative photographs. Due to limited resources, patients could not be offered longterm follow-up, but were invited to return back for review, if they experienced any problems. For the purpose of this study, patients were contacted by telephone to confirm, if any late complications had occurred.

\section{RESULTS}

Around 15 patients underwent augmentation rhinoplasty using Medpor ${ }^{\circledR}$ nasal implants, over 6 and half years period. These included nine males and six females with a mean age of 36 years (13-65 years). Patients underwent surgery to treat nasal deformities resulting from repeat surgeries, granulomatous disease, cartilage deteriorating traumas or prolonged drug (inhalant) use.

A total of $22 \mathrm{Medpor}^{\circledR}$ nasal implants were performed. These included dorsal, columella or alar nasal reconstructions via an external approach. All patients had a good initial surgical outcome. Three patients experienced a subsequent surgical complication, including one case of a slipped dorsal implant and two patients with graft extrusion.

Further analysis of predisposing factors that may have contributed to graft failures was conducted (Table 3 ). There were two patients who experienced extrusion of their grafts, and both these patients had concomitant disease processes that would have resulted in a poor tissue microenvironment. One of these patients had aggressive, underlying Wegener's granulomatosis. This patient's dorsal graft remained in place but the alar batten graft extruded after 12 months. The other patient had a previous history of cocaine abuse which had resulted in complete destruction of the cartilaginous nasal skeleton. This patient underwent complex nasal reconstruction requiring dorsal, columella and alar grafts. All grafts extruded over a period of time. Based on these observations, it is likely that an 'unhealthy' surrounding host tissue environment is an important predisposing factor that may have contributed to postoperative complications of graft failure.

All patients with normal, healthy tissues that had corrective surgery for deformities that resulted from previous surgery or trauma did very well with no complications of graft failure from extrusion.

\section{CASE REPORTS}

\section{Case 1}

A 45-year-old man was referred with a saddle nose deformity, which resulted from a previous septoplasty (Figs 1A and B). He underwent augmentation rhinoplasty using a Medpor ${ }^{\mathbb{B}}$ dorsal graft. A satisfactory outcome was obtained.

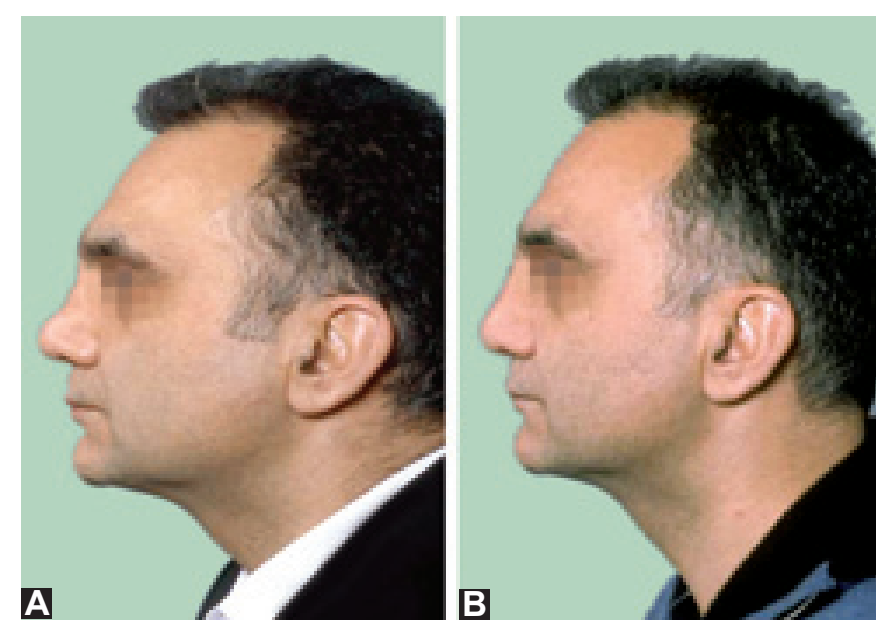

Figs 1A and B: (A) Preoperative lateral view showing saddle nose deformity. (B) Postoperative lateral view following reconstruction with Medpor $^{\circledR}$ dorsal implant (Case 1)

\section{Case 2}

A 13-year-old boy was referred with a saddle nose deformity (Figs 2A and B). He had previously sustained a traumatic injury to the face which had caused a septal hematoma. This had resulted in deterioration of his septal cartilage with loss of dorsum. He subsequently underwent nasal reconstruction using a Medpor ${ }^{\circledR}$ dorsal graft. He obtained a satisfactory result. 


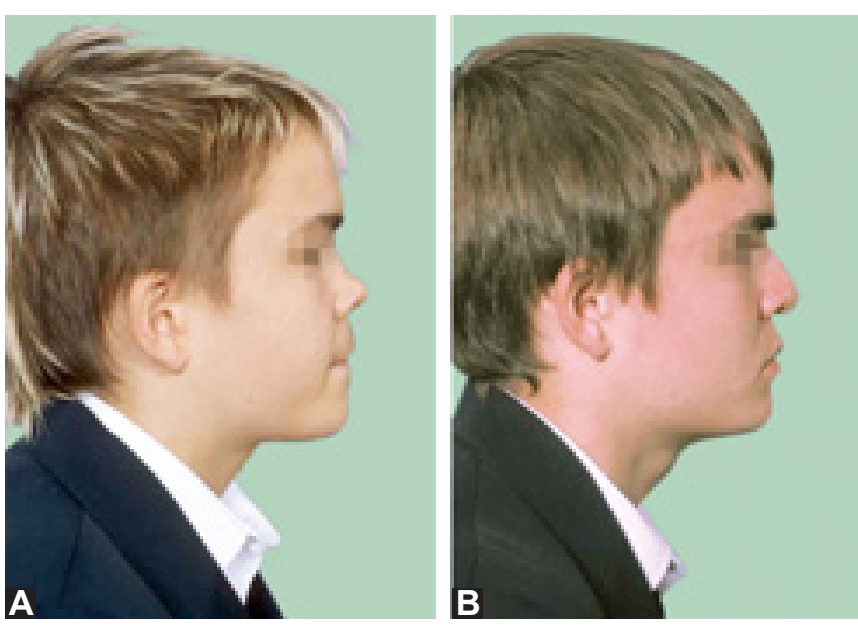

Figs 2 A and B: (A) Preoperative lateral view showing saddle nose deformity. (B) Postoperative lateral view following reconstruction with Medpor $^{\circledR}$ dorsal implant (Case 2)

\section{Case 3}

A 40-year-old lady with a background history of Wegener's granulomatosis, presented with significant nasal deformities that had resulted from her cartilage deteriorating condition (Figs 3A to D). She had suffered destruction of her septal cartilage, causing a saddle nose deformity, and also necrosis of her lower lateral cartilages, which was more significant on one side resulting in complete unilateral alar collapse. She underwent complex augmentation rhinoplasty to reconstruct her dorsum and left lower lateral cartilage using Medpor ${ }^{\circledR}$ nasal grafts. The patient's underlying granulomatous disease was very aggressive with multisystemic involvement. Subsequently, her alar graft rejected and extruded. It was fully removed under general anesthetic, and the patient relocated to another region, where she was due to undergo further reconstructive surgery.

\section{Case 4}

A 26-year-old man presented with a saddle nose deformity following a previous septal hematoma, associated with trauma to the nose (Figs $4 \mathrm{~A}$ to $\mathrm{D}$ ). He underwent reconstruction with a dorsal Medpor ${ }^{\circledR}$ implant which was inserted as an on-lay graft and secured with anchoring suture to the lower lateral cartilages. However, unfortunately this was unstable within the soft tissue pocket and, at 5 weeks, the patient presented again after noticing that the dorsum appeared asymmetrical. Clinical examination confirmed that the dorsal graft had slipped. The patient has been offered to have this repositioned and fixated using percutaneous Kwires.

\section{DISCUSSION}

Complex nasal deformities resulting in significant loss of the nasal skeleton often require large volumes of graft material. Autologous tissue remains the gold standard for nasal grafting material. It has unparalleled biocompatibility compared with alloplastic materials, and the subsequent risk of infection or protusion is far lower. ${ }^{13,14}$ For most nasal deformities, septal cartilage is the primary choice of graft material. It is available from the same surgical field with no significant additional morbidity associated with tissue harvest. Its only limitation is the limited availability, particularly in cases where the deformity results from loss of septum, as was the case in almost all patients in our series. Alternative autologous cartilage from the pinna can provide large quantities of cartilage, but it may have some contour irregularities which in our opinion makes it unsuitable for dorsal augmentation. It is also comparatively thin and weak, which we may make it less suitable for structural support.
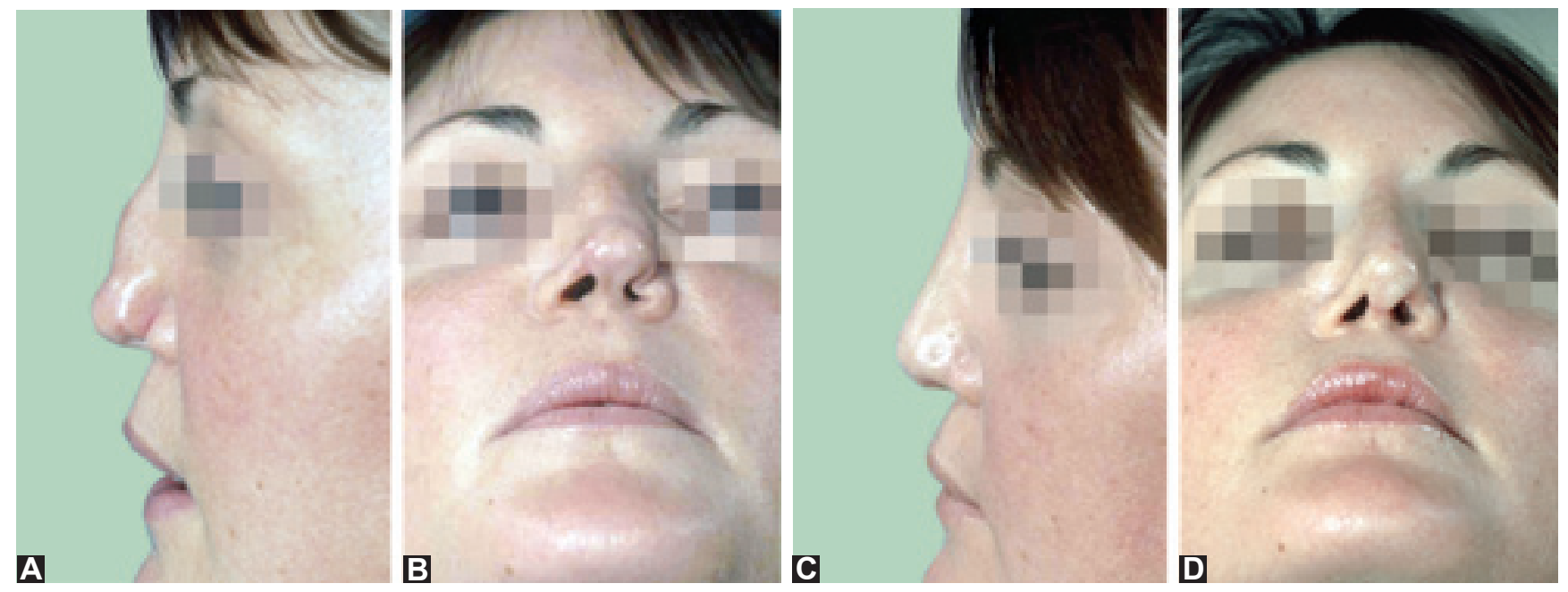

Figs 3 A to D: (A) Preoperative lateral view showing dorsal bony hump and loss of dorsal septal cartilage. (B) Preoperative basal view showing loss of left lower lateral cartilage resulting in alar collapse. (C) Postoperative lateral view following reconstruction of the cartilaginous dorsum with Medpor ${ }^{\circledR}$ implant. (D) Postoperative basal view after reconstruction of the left alar cartilage using Medpor ${ }^{\circledR}$ graft 

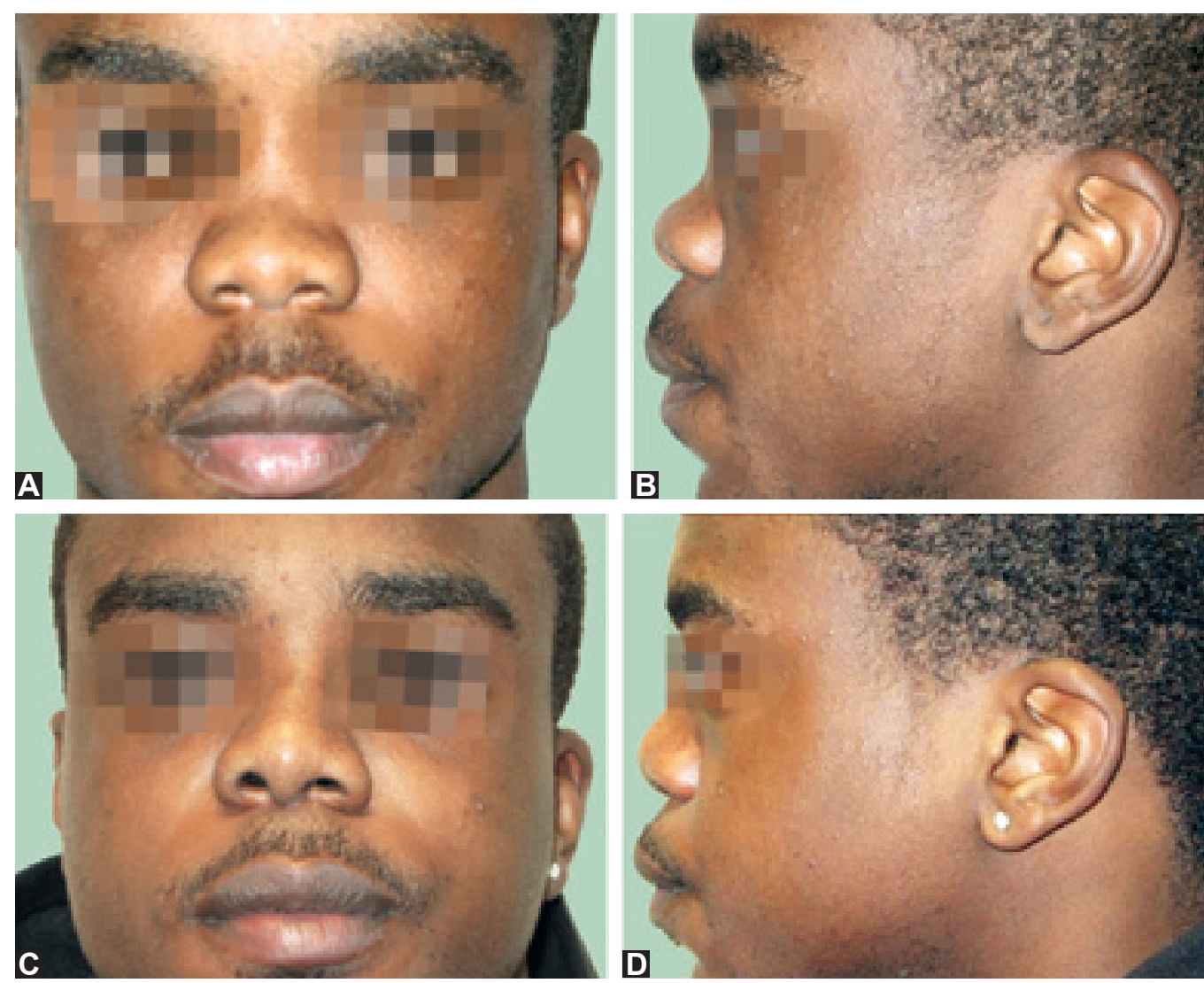

Figs 4A to D: (A) Preoperative frontal view showing a straight, wide dorsum. (B) Preoperative lateral view showing saddle nose deformity. (C) Postoperative frontal view at 5 weeks shows the slipped dorsal implant, resulting in scoliosis of the upper dorsum to the left. (D) Postoperative lateral view (5 weeks) following reconstruction with Medpor ${ }^{\circledR}$ dorsal implant, showing good dorsal support with satisfactory lateral profile

The other main source of autologous cartilage is from costal cartilage. Rib grafts can provide both cartilage and bone, and can yield large volumes. However, there is potentially significant morbidity associated with tissue harvest, including pain, a chest scar or possible pneumothorax. Rib cartilage grafts also have a recognized tendency to warp when used in the dorsum, leading to postsurgical deformity. Other sites of bone grafts from the iliac crest or calvarium also have similar donor site morbidity. In addition, bone grafts are naturally more rigid and harder to sculpt. For any of these alternative sources of autologous tissues, harvesting separate graft material from a different surgical site requires an additional incisional wound and has potential associated morbidity and risks, which maybe unacceptable to the patient or considered unnecessary by the surgeon. Furthermore, graft harvesting from a separate surgical field will require additional operative time.

In our opinion, septal cartilage remains the first choice of graft material for augmentation rhinoplasty with all other sources of autologous grafts being suboptimal for the reasons described above. In our patient series, all patients had insufficient quantities of septal cartilage available to provide tissue augmentation for their own deformities. An alternative alloplastic material Medpor ${ }^{\mathbb{B}}$ was therefore used.
Polyethylene is an inert material with low tissue reactivity, and is used as a standard material for biocompatibility testing. ${ }^{15}$ No implant degradation has been demonstrated by animal or clinical histological studies, and the foreign body reaction has been minimal. ${ }^{16,17}$ Porous polyethylene $\left(\right.$ Medpor $^{\mathbb{R}}$ ) is composed of a lattice open pore structure with an average pore size of $150 \mu \mathrm{m}(100-250 \mu \mathrm{m})$. Animal studies have shown that a pore size of $100 \mu \mathrm{m}$ or more allows maximal fibrous tissue in-growth and relative host tissue incorporation. ${ }^{16,17}$ This in-growth is important for two reasons, implant stabilization and infection control. Tissue in-growth limits movement of the graft with respect to its surrounding tissues, and reduces the potential risks of migration and protusion. Host tissue in-growth also minimizes dead spaces and facilitates transport of inflammatory cells to counteract bacterial colonization and potential infection. Furthermore, although porous in nature, the Medpor ${ }^{\circledR}$ graft does not lose rigidity and maintains skeletal support. Most importantly, as the Medpor ${ }^{\circledR}$ graft does not stimulate a significant foreign body reaction, it does not induce the natural host response of fibrous encapsulation, as is commonly experienced with silicone implants. Thus, the silicone implants are highly mobile, prone to extrusion and unable to resist infection. Complications 
from silicone implants include extrusion (2.9\%), infection (3.8\%), graft displacement $(9.8 \%)$ and drift of graft (76.5\%). ${ }^{18,19}$ Therefore, silicone is not considered as a suitable implant material in our practice, and is not used in our department. Gore-Tex ${ }^{\circledR}$ expanded polytetrafluoroethylene, (ePTFE) is another alternative alloplastic material which maybe considered. Like Medpor ${ }^{\circledR}$, it is also composed of a porous architecture (pore size 10-30 $\mu \mathrm{m}$ ), which allows tissue in-growth and therefore has similar advantages of graft stability and resistance to infection. It is a soft and pliable consistency, which provides good soft tissue augmentation, but its main limitation is that it lacks rigidity, and therefore provides limited structural support. However, the infection rate from Gore-Tex ${ }^{\circledR}$ is promising, after it was reduced from 3.2 to $1.3 \%$ after impregnation of the Gore$\mathrm{Tex}^{\circledR}$ in a bacitracin solution before implantation. ${ }^{20,21} \mathrm{We}$ have used a similar strategy by soaking our Medpor ${ }^{\circledR}$ implants in an antibiotic solution prior to placement.

Successful rhinoplasty using the Medpor ${ }^{\circledR}$ alloplastic implant has been widely described in different patient populations. It has been used in dorsal implantation, ${ }^{22,23}$ revision rhinoplasty, ${ }^{24,25}$ reconstruction of traumatic nasal deformities ${ }^{26}$ and corrective surgery for the bulbous tip. ${ }^{27}$ It has had variable complication rates reported ranging from 2.7 to $18 \% .{ }^{24,28-30}$ In particular rates of extrusion with the Medpor $^{\circledR}$ implant were reported to range from 0.5 to $4.3 \%$ and infection from 0 to $4.3 \%{ }^{26} \mathrm{~A}$ recent meta-analysis of the use of alloplastic materials used in rhinoplasty surgery was performed by Peled et al, which found that the removal rates for Gore-Tex ${ }^{\circledR}$ and Medpor ${ }^{\circledR}$ implants were both comparable at $3.1 \%$, compared with significantly higher rates of silicone graft removals at $6.5 \%{ }^{31}$

In our patient series, the Medpor ${ }^{\circledR}$ implant was chosen to provide structural augmentation to the nose. This was selected as the alloplastic material of choice, above all others, based on the numerous promising features described above. It was selected as the graft material in this patient cohort, where there was insufficient septal cartilage. Alternative autologous tissues were not considered due to their disadvantages and limitations already mentioned.

A total of 15 patients were included in our series, and these required a total of 22 Medpor $^{\circledR}$ grafts. The majority of grafts required were for dorsal augmentation (15 grafts) with an additional number of columellar graft (5 grafts) and a small number of alar batten grafts (2 grafts). Of these cases, we had one patient who experienced dorsal graft migration. The challenge in placement of the dorsal grafts is in securing it to adjacent upper lateral cartilages and residual septum. This case of graft migration highlights the importance of immobilization of the nasal alloplastic material. Chen et al also proposed suturing the distal end of the prosthesis to the lower lateral cartilages and in selected cases additional fixation of the implant with percutaneous K-wires for added stability, where it was felt that the graft was not wholly stabilized with simple suturing. ${ }^{26}$ We would now consider this strategy to secure unstable dorsal implants in selected cases to avoid this complication of graft migration.

Aside from this, we also had just two patients who experienced complications of graft extrusion. One of these patients had an aggressive granulomatous disease process, in whom the dorsal graft was satisfactory but the alar batten graft extruded (Case 3). The other patient had a previous history of cocaine abuse, in whom the dorsal, columellar and alar grafts all extruded. It is well-recognized that the potent vasoconstrictive effects of long-term cocaine inhalation results in chronic microvascular impairment and ischemia. ${ }^{32,33}$ Furthermore, the significant mucosal and cartilaginous impairment associated with chronic cocaine use has been recognized as a challenge for successful rhinoplasty surgery. ${ }^{34}$ Similarly, Wegener's granulomatosis is characterized by necrotizing granulomatous inflammation and vasculitis, which results in chronic microvascular damage. ${ }^{35}$ One of the important factors required for successful implantation should be a healthy surrounding tissue microenvironment. Both these patients had concomitant disease processes which were associated with poor vascularity in their host tissue and is likely to have contributed to their graft failures. Of note, there was also another patient in our series with a background history of Wegener's granulomatosis which was quiescent and well controlled, who required a dorsal graft alone and this patient had a satisfactory outcome. Therefore, in total there were three patients with concomitant diseases that resulted in their nasal deformities. These included two patients with Wegener's granulomatosis and one with the history of cocaine abuse. Between these three patients, there were three dorsal grafts performed, one columellar strut and two alar batten grafts. Interestingly, two of the three dorsal grafts were satisfactory, possibly suggesting that the dorsal implants are a more successful site of implantation, although a much larger patient cohort would need to be studied to validate this.

All other patients who underwent surgery using the Medpor ${ }^{\circledR}$ implant had a successful outcome. All patients who had nasal deformities resulting from previous septoplasty (9 patients) or septal hematomas (4 patients) did very well. Between them, they had a total of 12 dorsal implants and four columellar struts. None of these grafts at either site were complicated by graft infection or extrusion. This would support our impression that the surrounding tissue microenvironment is of crucial importance for graft 
success, and the presence of 'healthy' host tissue provides the most promising chance for a satisfactory result.

Based on our results, we would advocate the use of the porous polyethylene (Medpor ${ }^{\circledR}$ ) as providing an acceptable, safe alternative graft choice, when autogenous graft materials are considered inadequate or undesirable. Patients with comorbid disease processes that render significant nasal deformities are a challenging group to treat surgically. Their underlying suboptimal tissue microenvironment will reduce their chances of a satisfactory result, regardless of the graft choice that is utilized. However, for all other patients requiring complex augmentation rhinoplasty in a normal host tissue environment, the Medpor ${ }^{\circledR}$ implant has proved to be very successful. Its favorable characteristics include provision of adequate volume, rigidity and good support through its porous nature, thus facilitating rapid tissue ingrowth. We believe that it is a safe implant to use, and serves as a predictable alternative to autologous grafts, without any additional donor site morbidity.

\section{SUMMARY}

- Patients undergoing complex rhinoplasty following previous trauma or cartilage deteriorating disease processes present a surgical challenge

- Septal cartilage remains the gold standard for graft material, but its availability maybe limited

- A number of autologous and allograft materials are available for use as nasal graft material

- Porous polyethylene $\left(\right.$ Medpor $\left.^{\circledR}\right)$ implant provides a suitable alternative graft material with numerous favorable characteristics

- In our experience, the efficacy of porous polyethylene implants has proved to be very successful in patients with 'undiseased' tissue microenvironment.

\section{REFERENCES}

1. Merritt K, Shafer JW, Brown SA. Implant site infection rates with porous and dense materials. J Biomed Mater Res 1979; 13(1):101-08.

2. Wellisz T, Dougherty W, Gross J. Craniofacial applications for the Medpor porous polyethylene flexblock implant. J Craniofac Surg 1992;3(2):101-07.

3. Menderes A, Baytekin C, Topcu A, Yilmaz M, Barutcu A. Craniofacial reconstruction with high density porous polyethylene implants. J Craniofac Surg 2004;15(5):719-24.

4. Rubin PA, Bilyk JR, Shore JW. Orbital reconstruction using porous polyethylene sheets. Opthalmology 1994;101:1697-708.

5. Yilmaz M, Vayvada H, Aydin E, Menderes A, Atabey A. Repair of fractures of the orbital floor with porous polyethylene implants. Br J Oral Maxillofac Surg 2007;45(8):640-44.

6. Romo T III, Presti PM, Yalamanchili HR. Medpor alternative for microtia repair. Facial Plast Surg Clin North Am 2006;14(2):129-36.
7. Romo T III, Morris LG, Reitzen SD, Ghossaini SN, Wazen JJ, Kohan D. Reconstruction of congenital microtia-atresia: Outcomes with the Medpor/bone anchored hearing aid approach. Ann Plastic Surg 2009;62(4):384-89.

8. Berghaus A, Stelter K, Naumann A, Hempel JM. Ear reconstruction with porous polyethylene implants. Adv Otorhinolaryngol 2010;68:53-64.

9. Romo T III, Scalfani AP, Jacono AA. Nasal reconstruction using porous polyethylene implants. Facial Plast Surg 2000; 16(1): $55-61$.

10. Karnes J, Salisbury M, Schaeferle M. Porous high-density polyethylene implants (Medpor) for nasal dorsal augmentation. Aesthetic Surg J 2000;20:26-30.

11. Mendelsohn M. Straightening the crooked middle third of the nose: Using porous polyethylene extended spreader grafts. Arch Facial Plast Surg 2005;7(2):74-80.

12. Gurlek A, Ersoz-Ozturk A, Celik M, Firat C, Aslan S, Aydogan H. Correction of the crooked nose using custom made high density porous polyethylene extended spreader grafts. Aesthetic Plast Surg 2006;30(2):141-49.

13. Lovice DB, Mingrone MD, Toriumi DM. Grafts and implants in rhinoplasty and nasal reconstruction. Otolaryngol Clin North Am 1999;32:113-41.

14. Mass CS, Monhian N, Shah SB. Implants in rhinoplasty. Facial Plast Surg 1997;13:90.

15. Homsy CA. Biocompatability in selection of materials for implantation. J Biomed Mater Res 1970;4:341-56.

16. Spector M, Flemming WR, Sauer BW. Early tissue infiltrate in porous polyethylene implants into bone: A scanning electron microscope study. J Biomed Mater Res 1975;9:537-42.

17. Klawitter JJ, Bagwell JG, Weinstein Am, et al. An evaluation of bone growth into porous high density polyethylene. J Biomed Mater Res 1976;1:311-23.

18. Deva AK, Merten S, Chang L. Silicone in nasal augmentation rhinoplasty: A decade of clinical experience. Plast Reconstr Surg 1998;102:1230-37.

19. Zeng $\mathrm{Y}, \mathrm{Wu} \mathrm{W}, \mathrm{Yu} \mathrm{H}$, et al. Silicone implant in augmentation rhinoplasty. Ann Plast Surg 2002;49:495-99.

20. Godwin MS, Waldman SR, Johnson Jr CM. Nasal augmentation using Gore-Tex: A 10-year experience. Arch Facial Plast Surg 1999;1:118-21.

21. Conrad K, Torgerson CS, Gillman GS. Applications of GoreTex implants in rhinoplasty re-examined after 17 years. Arch Facial Plast Surg 2008;10:224-31.

22. Romo T III, Sclafani AP, Sabini P. Reconstruction of the major saddle nose deformity using composite alloimplants. Facial Plast Surg 1998;14(2):151-57.

23. Pham RT, Hunter PD. Use of porous polyethylene as nasal dorsal implants in Asians. J Cosmet Laser Ther 2006;8(2):102-06.

24. Romo T III, Sclafani AP, Sabini P. Use of porous high-density polyethylene in revision rhinoplasty and in the platyrrhine nose. Aesthetic Plast Surg 1998;22(3):211-21.

25. Turegun M, Acarturk TO, Ozturk S, Sengezer M. Aesthetic and functional restoration using dorsal saddle shaped Medpor implant in secondary rhinoplasty. Ann Plast Surg 2008;60(6): 600-03.

26. Chen CT, Hu TL, Lai JB, Chen YC, Chen YR. Reconstruction of traumatic nasal deformity in Orientals. J Plast Reconstr Aesthet Surg 2010;63(2):257-64.

27. Romo T III, Litner JA, Sclafani AP. Management of the severe bulbous nasal tip using porous polyethylene alloimplants. Facial Plast Surg 2003;19(4):341-48. 
28. Wellisz T, Dougherty W. The role of alloplastic skeletal modification in the reconstruction of facial burns. Ann Plast Surg 1993;30:531-36.

29. Turegun M, Sengezer M, Guler M. Reconstruction of saddle nose deformities using porous polyethylene implant. Aesthetic Plast Surg 1998;22:38-41.

30. Niechajev I. Porous polyethylene implants for nasal reconstruction: Clinical and histological studies. Aesthetic Plast Surg 1999;23:395-402.

31. Peled ZM, Warren AG, Johnston P, Yaremchuk MJ. The use of alloplastic materials in rhinoplasty surgery: A meta-analysis. Plast Reconstr Surg 2008;121(3):85e-92e.
32. Chow JM, ROberton AL, Stein RJ. Vascular changes in the nasal submucosa of chronic cocaine addicts. Am J Forensic Med Pathol 1990;11(2):136-43.

33. Patel R, Shah R, Baredes S, Spillert CR, Lazaro EJ. Nasal toxicity of cocaine: A hypercoagulable effect. J Natl Med Assoc. 2000;92:39-41.

34. Slavin SA, Goldwyn RM. The cocaine user: The potential problem patient for rhinoplasty. Plast Reconstr Surg 1990; 86(3): 436-42.

35. Cadoni G, Prelajade D, Campobasso E, Calo L, Agostino S, Manna R, Paludetti G. Wegener's granulomatosis: A challenging disease for otorhinolaryngologists. Acta Oto-Laryngologica 2005;125(10):1105-10. 